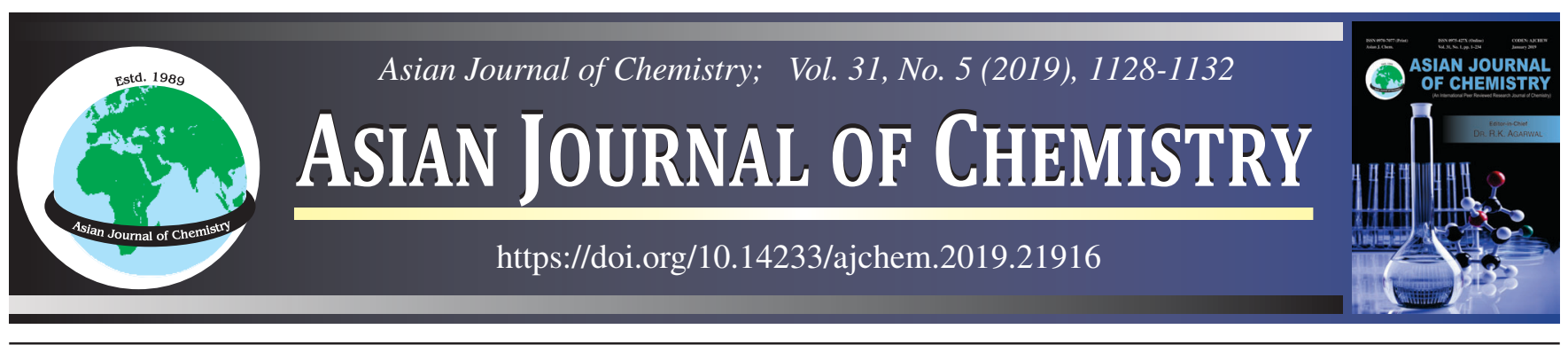

\title{
Geranium wallichianum Leaf Extract Mediated Synthesis of Silver Nanoparticles: Characterization and its Antimicrobial Activity
}

\section{P.P. Badoni ${ }^{1}$, Goutam Kumar ${ }^{1, *}$, Mahender Singh $^{1}, \mathrm{Navneet} \mathrm{Singh}^{2}$, Arun K. Khajuria ${ }^{3}$, Bharti ${ }^{4}$ and Sanjay Dutt $^{4}$}

${ }^{1}$ Department of Chemistry, Hemvati Nandan Bahuguna Garhwal University, BGR Campus, Pauri-246001, India

${ }^{2}$ Department of Chemistry, Hemvati Nandan Bahuguna Garhwal University, Birla Campus, Srinagar-246174, India

${ }^{3}$ Department of Botany, Hemvati Nandan Bahuguna Garhwal University, BGR Campus, Pauri-246001, India

${ }^{4}$ Department of Chemistry, Hemvati Nandan Bahuguna Garhwal University, SRT Campus, Tehri-249199, India

*Corresponding author: E-mail: goutamkmmrr17@gmail.com

Received: 5 January 2019; Accepted: 22 January 2019;

Published online: 28 March 2019;

AJC-19342

\begin{abstract}
In present study, the Geranium wallichianum leaf extract (aqueous) and $1 \mathrm{mM}$ silver nitrate solution (aqueous) were amalgamated to synthesize silver particles within the nanometer range. Initial colour changes and surface-plasmon-resonance (SPR) absorbance band observed in UV-visible spectroscopic study gave support to configuration of silver nano-particles. Silver nanoparticles were characterized by XRD, TEM and FTIR spectroscopy. Then antimicrobial (antibacterial and antifungal) activities of silver nanoparticles against selected microbial strains were studied by well diffusion method. During this work, silver SPR absorption bands between $405-425 \mathrm{~nm}$ range were shown by Geranium wallichianum leaf extract mediated synthesized silver nanoparticles sample solutions at different intervals. X-ray diffraction pattern displayed the formation of face centred cubic phase silver nano-structures. TEM measurements confirmed that silver nanoparticles are spherically shaped and maximum particles in 9-16 nm size range having average diameter $12.5 \mathrm{~nm}$. Important FT-IR peaks at $3314.11,1710.60,1587.11$ and $1347.77 \mathrm{~cm}^{-1}$ were predicted for hydroxyl, carbonyls, unsaturated C-C bonds and phenolic groups respectively. Further from antimicrobial results, it has been found that values of diameter of zone of inhibition (mm) of synthesized silver nanoparticles against $B$. subtilis, S. aureus, L. plantarum, P. aeruginosa, A. niger and C. albicans strains were 32, 28, 25, 25 35 and not active, respectively. MIC-MLC $(\mu \mathrm{L})$ values were also determined. At last, it can be concluded that antimicrobial agents of 9-16 nm size range and stabilized by polyhydroxy-bioactive-components present in extract, in the form of silver nanoparticles has been productively synthesized.
\end{abstract}

Keywords: Silver nanoparticles, Surface plasmon resonance, Antimicrobial agents, Polyhydroxy bioactive components.

\section{INTRODUCTION}

Nanoscience is a new and innovative inter-disciplinary area under discussion which is based on the elementary properties of nano-size structures [1,2]. Nanoparticles own unbelievable and amazing optical, electronic, magnetic, catalytic and many more properties than the large sized objects owing to their high surface area to volume ratio [3,4]. Metallic nanoparticles are developed by a variety of methods but commonly repeated are physical and chemical routes. The aforesaid routes create clean and well-defined nanoparticles, but the chemicals applied in the creation are deadly, energy consuming, high cost and not appropriate for biological purposes. Metallic nanoparticles are developed in the past three decades, but research on nano- particles creation through plant extract has been boomed only in the last decade. Plants are considered as green nanofactories and amalgamation of silver nanoparticles through plants and their utilization in associated field has become the primary curiosity of scientists from different regions and logics. The main advantage of applying plant extracts for developing of nanoparticles is their easily accessibility, safe and sound, and are faster than microbes in the worth production. The whole plant and/or their parts such as seed, root, leaf, stem, bark, fruit, pulp, etc. were previously applied for bio-inspired creation of silver nanoparticles [5-10]. During the reaction of silver salt and plant extract, $\mathrm{Ag}^{+}$ions may be encircled by - $\mathrm{OH}$ and $-\mathrm{COOH}$ groups of plant phenolics; there is the possibility of reduction of silver salt and/ or capping of $\mathrm{Ag}^{+}$ions by phenolics $[11,12]$.

This is an open access journal, and articles are distributed under the terms of the Creative Commons Attribution-NonCommercial-ShareAlike 4.0 (CC BY-NC-SA 4.0) International License which allows readers to freely read, download, copy, distribute, print, search, or link to the full texts of its articles and to use them for any other lawful non-commercial purpose as long as the original source is duly acknowledged. 
Silver with medical and therapeutic benefits has long history and also used in numerous forms as coins, containers, sols, layers, and in many more articles. It is a key remedial agent in medicine for deadly infections and profits of silver are much more than the threats [13-16].

After reviewing data, it has been assumed that no such report has been texted regarding the synthesis of silver nanoparticles by using aqueous leaf extract of Geranium wallichianum. Geranium wallichianum is commonly known as Ratanjot or Laljari, belongs to Geraniaceae. It is a perennial herb to $80 \mathrm{~cm}$ tall and rootstock woody. Leaves orbicular, $3-13 \mathrm{~cm}$ across, palmately lobed; segments deeply or irregularly toothed with acute tip and light purpled flowers [17]. It exhibited a variety of biological activities, such as antibacterial, antifungal, cytotoxic, phytotoxic, insecticidal and enzyme inhibition [18]. The whole plant extract of $G$. wallichianum was fractionated by silica gel column chromatography and isolated one triterpene, three steroids, one coumarin and one benzoic acid derivative [19]. Hence, present work is designed to amalgamate silver nano-particles through leaf extract (aq.) of this valuable plant and $1 \mathrm{mM}$ silver nitrate solution.

\section{EXPERIMENTAL}

Analytical grade chemicals were procured from SigmaAldrich company. Deionized distilled water was used in all experiments. Plant (G. wallichianum) specimen was collected from Adwani, Pauri (Garhwal), India and authenticated from Garhwal University Herbarium and its voucher specimens (GUH20757) were deposited.

Culture media: Soyabean casein digest and Sabouraud's dextrose broth of Hi Media Pvt. Bombay, India were used for antibacterial and antifungal test, respectively.

Microorganisms: Pure cultures of bacteria viz. Bacillus subtilis, Staphylococcus aureus, Lactobacillus plantarum and Pseudomonas aeruginosa and fungi viz. Aspergillus niger and Candida albicans were used for the tests.

Preparation of Geranium wallichianum leaf extract: Fresh leaves of $G$. wallichianum were cleaned numerous times with deionized distilled water to take out any of the adhering pathogens/ dirt and subsequently incised into very small pieces, placed in an oven keeping its fan on at $40^{\circ} \mathrm{C}$ and then mashed to powder form using mortar-pestle. Geranium wallichianum leaves powder $(5 \mathrm{~g})$ was added in a $250 \mathrm{~mL}$ Erlenmeyer flask and then 100 $\mathrm{mL}$ deionized distilled water was added to it. The flask was heated for 20-25 min at $70{ }^{\circ} \mathrm{C}$. Finally, resulted leaf extract was filtered in a separate conical flask and stored for further steps.

Synthesis of silver nanoparticles: In a 5 L Erlenmeyer flask, 1:9 mixture of Geranium wallichianum leaf extract and $1 \mathrm{mM} \mathrm{AgNO}_{3}$ solution (aqueous) was prepared. It was kept for $24 \mathrm{~h}$ in the dark place for the amalgamation. The colour of solution changed to dark red, indicating the formation of silver nanoparticles. Then, the solution was centrifuged for $10 \mathrm{~min}$ at $5000 \mathrm{rpm}$, also with water and ethanol, to take away unreacted/ uncoordinated material. And at last, centrifuged material was dessicated in the oven at $65^{\circ} \mathrm{C}$ and greyish black material of silver nanoparticles was collected.

Determination of antimicrobial activity: Soyabean casein digest broth was used to inoculate into bacteria and incubation temperature was kept at $37^{\circ} \mathrm{C}$ for $18 \mathrm{~h}$ and further suspension was checked to provide approximately, $10^{8} \mathrm{CFU} / \mathrm{mL}$. The same steps were followed for fungal strains but inoculation was carried into Sabouraud's dextrose broth and further incubated at $48-72 \mathrm{~h}$.

Diameter of zone of inhibition by well diffusion method: Bacterial culture in soyabean casein digest agar medium (SCDM) was inoculated and separately suspended in broth. Wells of 8 $\mathrm{mm}$ diameter were punched into agar and loaded with nanoparticles solution (in DMSO) and solvent blanks. Erythromycin, $(1 \mathrm{mg} / \mathrm{mL})$ was concurrently applied as the positive control and DMSO as negative control. Then the plates were incubated at $37^{\circ} \mathrm{C}$ for $18 \mathrm{~h}$. The antibacterial activity was estimated by measuring the diameter of zone of inhibition [20]. For assaying, antifungal activity of nanoparticles solution, Sabouraud's dextrose broth medium plates were utilized. The same procedure as that for determination of antibacterial activity was implemented and diameter of zone of inhibition was measured after 48-72 h. Fluconozole $(1 \mathrm{mg} / \mathrm{mL})$ was applied as standard. The procedure for assaying antimicrobial activity was carried out in triplicates to confirm the readings of diameter of zone of inhibition for each of the test microbe.

Minimum inhibitory and minimum lethal concentration: In sterile DMSO, nanoparticles solution $(100 \mu \mathrm{L})$ was prepared and successively diluted with $\mathrm{N}$-saline $(0.85 \% \mathrm{NaCl})$ and similar amount of bacterial or fungal suspension was added to different test-tubes and kept for $48 \mathrm{~h}$ incubation period [21,22].

Characterization: Initially, at regular intervals of time, creation of nano silver was assured using Elite-UV-visible spectrophotometer. The formation of silver nanoparticles was screened from 300 to $700 \mathrm{~nm}$ range against aqueous leaf extract (as blank) and plotted.

Nano silver powder was subjected to XRD analysis (X'PERT-PRO Diffractometer, PANalytical; $\mathrm{CuK}_{\alpha}$ radiation, $\lambda_{\max }=1.54 \AA$ ). In XRD, X-rays penetrate into powdered sample that results in a diffraction pattern (if, $n \lambda=2 \mathrm{~d} \sin \theta$ ). The morphology of silver nanoparticles was determined by transmission electron microscope (JEOL JEM 1011, 100kva ). Nano silver powder was analyzed for spectral measurements using FT-IR Spectrophotometer Perkin Elmer Model RZX. FT-IR spectral analysis is applied in order to recognize the possible bioactive components reliable for the capping and effective stabilization of nanomaterial.

\section{RESULTS AND DISCUSSION}

In this work, Geranium wallichianum leaf extract (aqueous) which is rich in polyhydroxy biocomponents (stigmasterol, $\beta$-sitosterol, herniarin, 2,4,6-trihydroxy ethylbenzoate, etc.) was used to synthesize silver nanoparticles. Moreover, biocomponents in the leaf extract not only helped to reduce $\mathrm{Ag}^{+}$ ions but also performed a key role in stabilizing nanoparticles. Fig. 1 shows the UV-visible spectrum which confirmed the presence of nano-Ag structures in the solution. The conversion of $\mathrm{Ag}^{+}$ions into silver nanoparticles has been checked by UVvisible spectroscopy and due to plasmonic vibrations in silver surfaced with biocomponents, its suspension displayed reddish brown colour. In this section, broad absorbance band appeared at $\lambda_{\max }=405-425 \mathrm{~nm}$ which is possibly due to slow amalgama- 


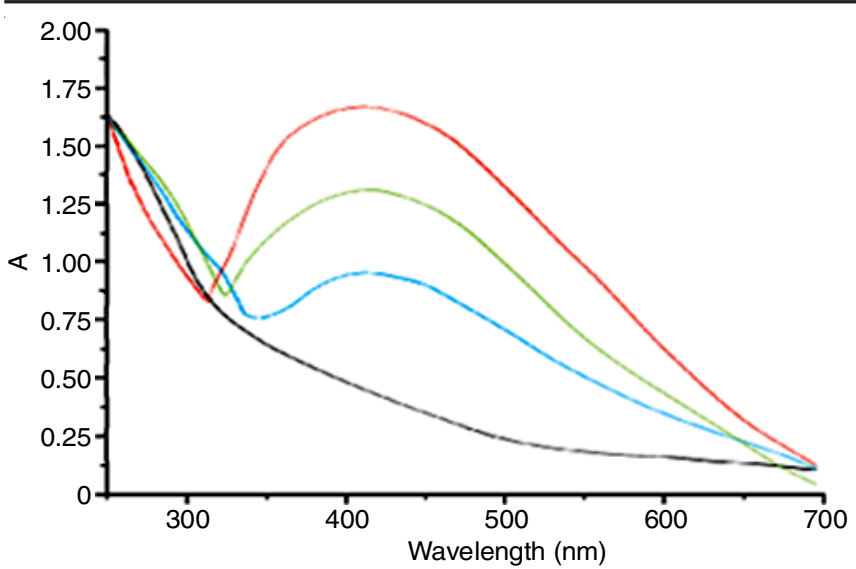

Fig. 1. UV-visible spectrum of silver nanoparticles after $5 \mathrm{~min}, 3 \mathrm{~h}, 12 \mathrm{~h}$ and $24 \mathrm{~h}$ intervals of time

tion nano-silver phases and polydispersed silver nanoparticles. Its calculated energy band gap is between 2.91-3.06 eV. The XRD pattern of nano powder showed three distinctive peaks at $2 \theta=28.82^{\circ}, 32.83^{\circ}, 38.68^{\circ}, 44.83^{\circ}$ and $64.99^{\circ}$ which are indexed to (2 10$)$, (1 13$)$ (1 111 ), (2 00 ) and (2 20$)$ of face centred cubic (fcc) nano-Ag crystals, respectively (Fig. 2) [2-5,7,23] and the weak intensities of peaks with slight dislocation indicates that silver nanocrystals are embedded in the film. Morphology of nano-Ag structures was studied by TEM (Fig. 3). These measurements confirmed that nano-Ag structures were spherically shaped and maximum particles in $9-16 \mathrm{~nm}$ size range with average diameter $12.5 \mathrm{~nm}$. Furthermore, FT-IR analysis of silver nanoparticles synthesized by using G. wallichianum leaf extract evidenced capping by biocomponents. Important FT-IR peaks at 3314.11, $1710.60,1587.11$ and $1347.77 \mathrm{~cm}^{-1}$ are due to $-\mathrm{OH},-\mathrm{C}=\mathrm{O},-\mathrm{C}=\mathrm{C}$ and $\mathrm{Ar}-\mathrm{OH}$, respectively. In the silver nanoparticles spectrum (Fig. 4), peak at $3314.11 \mathrm{~cm}^{-1}$ shows that phenolic $(\mathrm{O}-\mathrm{H})$ hydrogen is not eliminated and $\mathrm{C}=\mathrm{O}$ overtone could be seen at $1710.60 \mathrm{~cm}^{-1}$, while the band at $1587.11 \mathrm{~cm}^{-1}$ is due to $-\mathrm{C}=\mathrm{C}$ ring residues and peak at 1347.77 $\mathrm{cm}^{-1}$, supporting the presence of phenolic groups. From FT-IR

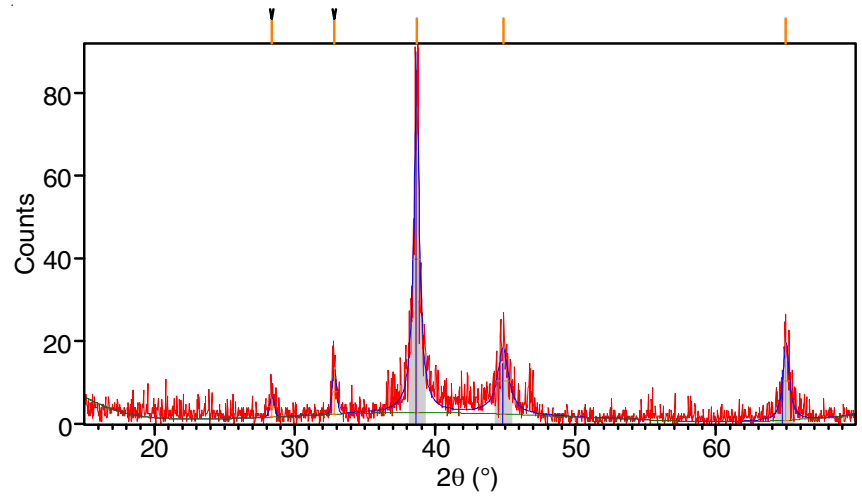

Fig. 2. XRD pattern of silver nanoparticles

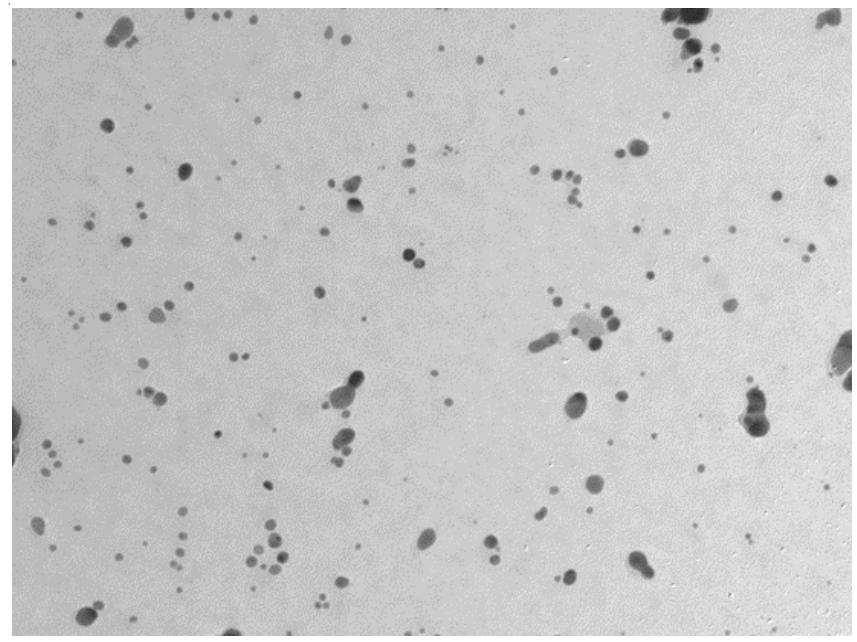

Fig. 3. Transmission electron micro-image of silver nanoparticles

data, it could be thought that 2,4,6-trihydroxy-ethylbenzoate may be playing a significant part in the synthesis of bio-inspired silver nanoparticles. Hence, FT-IR spectral investigation discloses the multi-functionality of the leaf extract (aq.) and also supports the existence and role of 2,4,6-trihydroxyethylbenzoate bio-component in the reduction or attachment on

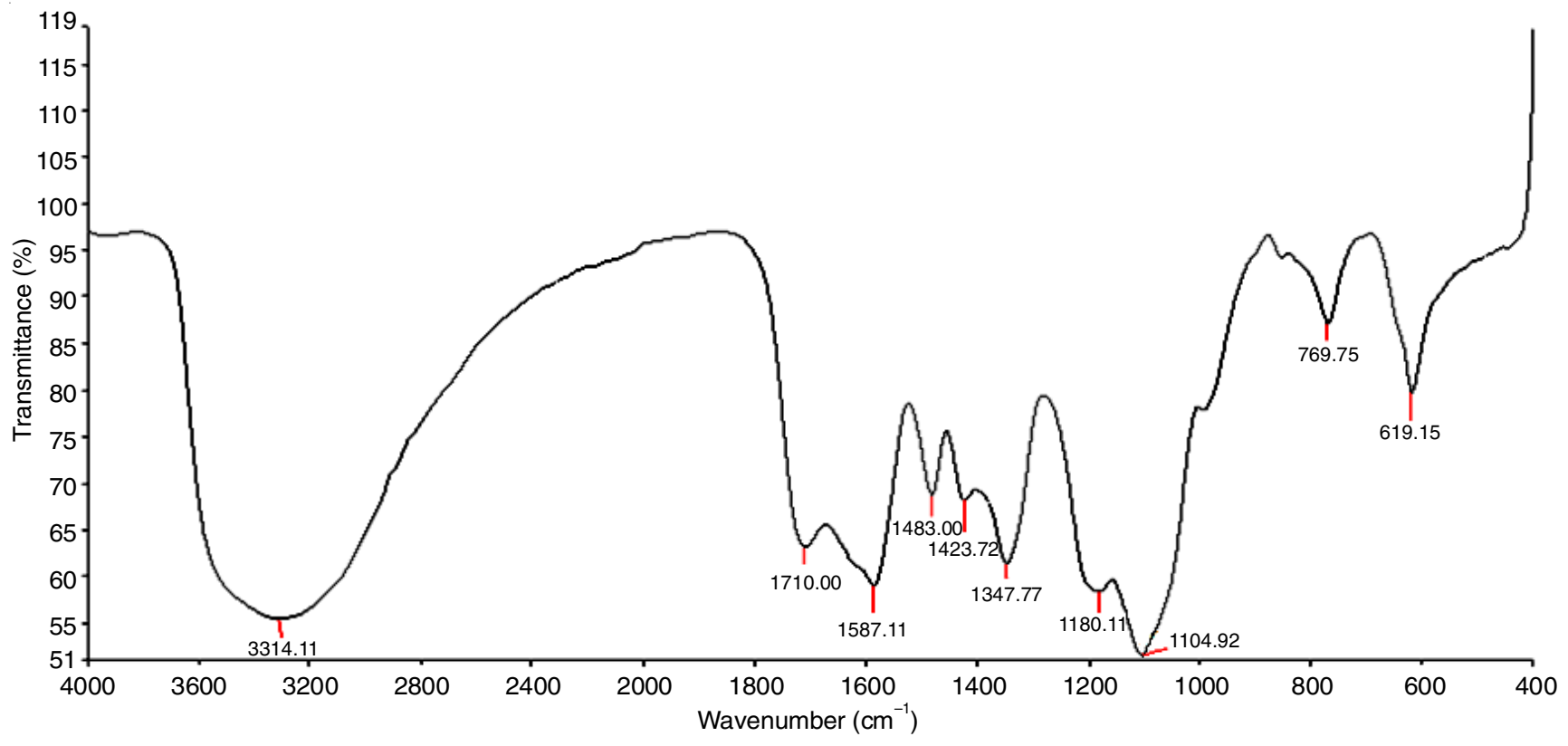

Fig. 4. FTIR spectrum of silver nanoparticles 
TABLE-1

VALUES OF DIAMETER OF ZONE OF INHIBITION AND MIC-MLC AGAINST SELECTED MICROBIAL STRAINS

\begin{tabular}{|c|c|c|c|c|c|c|c|c|c|c|c|c|}
\hline \multirow[b]{2}{*}{ Sample } & \multicolumn{12}{|c|}{ Diameter of zone of inhibition (mm) } \\
\hline & \multicolumn{2}{|c|}{$\begin{array}{c}\text { B. subtilis } \\
\text { (NCFT.583.08) }\end{array}$} & \multicolumn{2}{|c|}{$\begin{array}{c}\text { S. aureus } \\
\text { (NCFT.576.08) }\end{array}$} & \multicolumn{2}{|c|}{$\begin{array}{c}\text { L. plantarum } \\
\text { (NCFT.623.34) }\end{array}$} & \multicolumn{2}{|c|}{$\begin{array}{c}\text { P. aeruginosa } \\
\text { (NCFT.645.11) }\end{array}$} & \multicolumn{2}{|c|}{$\begin{array}{c}\text { A. niger } \\
\text { (NCFT.623.11) }\end{array}$} & \multicolumn{2}{|c|}{$\begin{array}{c}\text { C. albicans } \\
\text { (NCFT.1006.11) }\end{array}$} \\
\hline Silver nanoparticles $(100 \mu \mathrm{L})$ & \multicolumn{2}{|c|}{32} & \multicolumn{2}{|c|}{28} & \multicolumn{2}{|c|}{25} & \multicolumn{2}{|c|}{25} & \multicolumn{2}{|c|}{35} & \multicolumn{2}{|c|}{ Not active (NA) } \\
\hline Erythromycin $(1 \mathrm{mg} / \mathrm{mL})$ & \multicolumn{2}{|c|}{45} & \multicolumn{2}{|c|}{34} & \multicolumn{2}{|c|}{35} & \multicolumn{2}{|c|}{38} & \multicolumn{2}{|c|}{ Not tested (NT) } & \multicolumn{2}{|c|}{ NT } \\
\hline \multirow[t]{3}{*}{ Flucanozole $(1 \mathrm{mg} / \mathrm{mL})$} & & & & & & & & & & & & \\
\hline & \multicolumn{12}{|c|}{ MIC and MLC $(\mu \mathrm{L})$} \\
\hline & MIC & MLC & MIC & MLC & MIC & MLC & MIC & MLC & MIC & MLC & MIC & MLC \\
\hline Silver nanoparticles & 80 & 90 & 95 & 100 & 90 & 100 & 28 & 45 & 35 & 45 & NA & NA \\
\hline
\end{tabular}

the surface of silver ions to stabilize the finally developed nanoAg structures.

Antimicrobial activity: Diameter of zone of inhibition $(\mathrm{mm})$ is measured against B. subtilis, S. aureus, L. plantarum, P. aeruginosa, A. niger and C. albicans strains (Table-1). The results of antimicrobial tests evidenced to higher antibacterial activity of biosynthesized silver nanoparticles against $B$. subtilis but lower for $L$. plantarum and $P$. aeruginosa. The plant assisted developed silver nanoparticles have plainly showed the membrane injuries in Candida sp. and some harms in the intercellular parts and ultimately leads to cell death [24]. Silver nanoparticles amalgamated in this work have shown efficient response against $A$. niger and negligible for $C$. albicans. Nano-silver structures have great prospective than industrial antibiotics such as fluconazole. To further expand the tests for the measurement of biostatic and biocidal effects of silver nanoparticles, MIC and $\operatorname{MLC}(\mu \mathrm{L})$ values were also measured (Table-1) and shown by activity histogram (Fig. 5). It shows bio-based silver nanoparticles are a brilliant biostatic and/ or biocidal element.

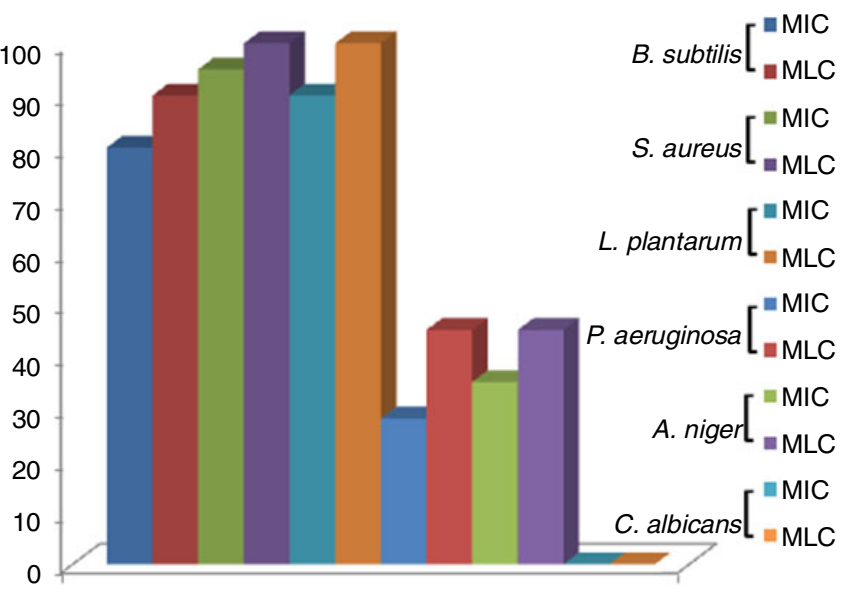

Fig. 5. Histogram of MIC-MLC of silver nanoparticles

Though a mixture of assumptions have been proposed to clarify the mode of silver nanoparticles, but widely believed one is that these interact to the cell wall and puncture it, which results in outflow of intracellular material and in the end leads to cell death [25]. Another study supported that $\mathrm{Ag}^{+}$ions, undergoes electrostatic attraction between negatively charged cell membrane of microbes [26]. Furthermore, the researchers attempted the tests in dark and suggested that only an ambient laboratory settings could manage the finest microbial effects; also reduced dimension and quantity advanced this effect. The different conditions, including the variety of culture medium and the microbial cells number, contribute to the fluctuation in antimicrobial activity grades $[27,28]$. Thus, further research is needed to look into the precise mechanisms to authentically illuminate the sensitivity of microbes to nanostructures, as the results are fairly promising.

\section{Conclusion}

It can be concluded that rapid, environment friendly and single step reaction to amalgamate silver nanoparticles using Geranium wallichianum leaf extract (aq.) has been promoted. Spherically shaped silver in 9-16 $\mathrm{nm}$ size range having average diameter $12.5 \mathrm{~nm}$ are synthesized. It is proposed that hydroxyl group containing 2,4,6-trihydroxyethylbenzoate component may be responsible as an active reductant and capping agent. Thus, this route is a hopeful substitute to the long-established reduction routes to evade practice of toxic chemicals.

\section{ACKNOWLEDGEMENTS}

The authors acknowledge to IARI-New Delhi, Panjab University, Chandigarh and UGC, Delhi, India for providing TEM, FTIR and granting funds, respectively. The authors are also grateful to National Centre of Fungal Taxonomy, New Delhi, India for conducting the antimicrobial tests.

\section{CONFLICT OF INTEREST}

The authors declare that there is no conflict of interests regarding the publication of this article.

\section{REFERENCES}

1. K.M.M. Abou El-Nour, A. Eftaiha, A. Al-Warthan and R.A.A. Ammar, Arab. J. Chem., 3, 135 (2010); https://doi.org/10.1016/j.arabjc.2010.04.008

2. P. Mohanpuria, N.K. Rana and S.K. Yadav, J. Nanopart. Res., 10, 507 (2008); https://doi.org/10.1007/s11051-007-9275-x.

3. S. Poulose, T. Panda, P.P. Nair and T. Theodore, J. Nanosci. Nanotechnol., 14, 2038 (2014);

https://doi.org/10.1166/jnn.2014.9019.

4. M. Vijayakumar, K. Priya, F.T. Nancy, A. Noorlidah and A.B.A. Ahmed, Ind. Crops Prod., 41, 235 (2013); https://doi.org/10.1016/j.indcrop.2012.04.017.

5. M. Ghaffari-Moghaddam, R. Hadi-Dabanlou, M. Khajeh, M. Rakhshanipour and K. Shameli, Korean J. Chem. Eng., 31, 548 (2014); https://doi.org/10.1007/s11814-014-0014-6.

6. M.A. Faramarzi and A. Sadighi, Adv. Colloid Interface Sci., 189-190, 1 (2013);

https://doi.org/10.1016/j.cis.2012.12.001.

7. S. Azizi, F. Namvar, M. Mahdavi, M. Ahmad and R. Mohamad, Materials, 6, 5942 (2013); https://doi.org/10.3390/ma6125942.

8. Prasad, V.S.R. Kambala and R. Naidu, J. Appl. Phycol., 25, 177 (2013); https://doi.org/10.1007/s10811-012-9851-z. 
9. R. Das, S.S. Nath, D. Chakdar, G. Gope and R. Bhattacharjee, J. Exp. Nanosci., 5, 357 (2010); https://doi.org/10.1080/17458080903583915.

10. M. Gilaki, J. Biol. Sci., 10, 465 (2010); https://doi.org/10.3923/jbs.2010.465.467.

11. K. Jagajjanani Rao and S. Paria, Mater. Res. Bull., 48, 628 (2013); https://doi.org/10.1016/j.materresbull.2012.11.035.

12. A. Tripathy, A.M. Raichur, N. Chandrasekaran, T.C. Prathna and A. Mukherjee, J. Nanopart. Res., 12, 237 (2010); https://doi.org/10.1007/s11051-009-9602-5.

13. V.K. Sharma, R.A. Yngard and Y. Lin, Adv. Colloid Interface Sci., 145, 83 (2009); https://doi.org/10.1016/j.cis.2008.09.002.

14. Q.H. Tran, V.Q. Nguyen and A.-T. Le, Sci.: Nanosci. Nanotechnol., 4, 033001 (2013); https://doi.org/10.1088/2043-6262/4/3/033001.

15. Y.A. Krutyakov, A.A. Kudrinskiy, A.Y. Olenin and G.V. Lisichkin, Russ. Chem. Rev., 77, 233 (2008); https://doi.org/10.1070/RC2008v077n03ABEH003751.

16. D.R. Monteiro, L.F. Gorup, A.S. Takamiya, A.C. Ruvollo-Filho, E.R. Camargo and D.B. Barbosa, Int. J. Antimicrob. Agents, 34, 103 (2009); https://doi.org/10.1016/j.ijantimicag.2009.01.017.

17. R.D. Gaur, Flora of the District Garhwal, North West, p. 386 (1999).

18. M. Ismail, J. Hussain, A. Khan, A.L. Khan, L. Ali, F. Khan, A.Z. Khan, U. Niaz and I. Lee, Evid.-Based Complem. Altern. Altern. Med., 2012, Article ID 305906 (2012); https://doi.org/10.1155/2012/305906.
19. M. Ismail, M. Ibrar, Z. Iqbal, J. Hussain, H. Hussain, M. Ahmed, A. Ejaz and M.I. Choudhary, Rec. Nat. Prod., 3, 193 (2009).

20. C. Perez and C. Anesini, J. Ethnopharmacol., 44, 41 (1994); https://doi.org/10.1016/0378-8741(94)90097-3.

21. H. Usman, F.I. Abdulrahman and A.H. Ladan, Res. J. Biol. Sci., 2, 244 (2007).

22. A.D. Vollekova, D. Koštálová and R. Sochorová, Folia Microbiol., 46, 107 (2001); https://doi.org/10.1007/BF02873586.

23. L. Karthik, G. Kumar, A.V. Kirthi, A.A. Rahuman and K.V. Bhaskara Rao, Bioprocess Biosyst. Eng., 37, 261 (2014); https://doi.org/10.1007/s00449-013-0994-3.

24. P. Logeswari, S. Silambarasan and J. Abraham, J. Saudi Chem. Soc., 15, 311 (2015); https://doi.org/10.1016/j.jscs.2012.04.007.

25. P.K. Stoimenov, R.L. Klinger, G.L. Marchin and K.J. Klabunde, Langmuir, 18, 6679 (2002); https://doi.org/10.1021/la0202374.

26. P. Dibrov, J. Dzioba, K.K. Gosink and C.C. Häse, Antimicrob. Agents Chemother., 46, 2668 (2002); https://doi.org/10.1128/AAC.46.8.2668-2670.2002.

27. O. Yamamoto, Int. J. Inorg. Mater., 3, 643 (2001); https://doi.org/10.1016/S1466-6049(01)00197-0.

28. Y. Xie, Y. He, P.L. Irwin, T. Jin and X. Shi, Appl. Environ. Microbiol., 77, 2325 (2011); https://doi.org/10.1128/AEM.02149-10. 